\title{
Haemodynamic responses to isometric exercise (handgrip) in patients with heart disease ${ }^{1}$
}

\author{
Michael L. Fisher, Donald O. Nutter, William Jacobs, and Robert C. Schlant \\ From the Division of Cardiology, Department of Medicine, Emory University School of Medicine \\ and the Grady Memorial Hospital, Atlanta, Georgia, U.S.A.
}

The haemodynamic responses to isometric handgrip exercise in 72 patients with heart disease were studied during cardiac catheterization. The results confirm observations in normal man, showing that isometric exercise imposes a sudden and significant stress on the cardiovascular system. During isometric handgrip exercise ( $25 \%$ of maximum voluntary contraction for 5 minutes or $75 \%$ for one minute), the heart rate increased by an average of $I 7$ beats a minute $(20 \%)$, mean systemic pressure increased by $22 \mathrm{mmHg}(23 \%)$, and the cardiac index increased by $470 \mathrm{ml}(18 \%)$, with inconsistent changes in total systemic resistance. Isometric handgrip exercise had little effect on left ventricular end-diastolic pressure in patients with normal LV function or mitral stenosis whereas in patients with abnormal $L V$ function the average end-diastolic pressure increased by $7 \cdot I$ $\mathrm{mmHg}$ (from 18.2 to $25.3 \mathrm{mmHg}$ ). In patients with normal $\mathrm{LV}$ function isometric handgrip exercise had little effect on mean pulmonary arterial pressure but in patients with mitral stenosis or abnormal LV function mean pulmonary artery pressure rose by $8.0 \mathrm{mmHg}(2 \mathrm{I} \%)$ and $6.8 \mathrm{mmHg}(26 \%)$, respectively. Isometric handgrip exercise evoked a lesser increase in heart rate and cardiac output than did submaximal dynamic (treadmill) exercise but resulted in a more potent systemic pressor response. Isometric handgrip exercise was not accompanied by complications in this study and appears to be a simple manoeuvre for cardiac stress testing.

Isometric (static) exercise is performed as part of many daily activities. Studies in healthy young subjects have shown that a potent cardiovascular reflex adjustment rapidly occurs during sustained static exercise (Tuttle and Horvath, 1957; Lind et al., 1964; Donald et al., 1967; Lind and McNicol, 1967a; Freyschuss, 1970). Compared to dynamic exercise, the reflex increase in heart rate and cardiac output is modest whereas a conspicuous increase occurs in mean systemic blood pressure. Lind and $\mathrm{McNicol}$ (1967a) have shown that the magnitude of haemodynamic changes occurring during static exercise seems to depend upon the relative strength of contraction, i.e. the proportion of maximal effort employed, and on the duration of contraction. Within wide limits the cardiovascular reflex is independent of the mass of contracting muscle (Lind and $\mathrm{McNicol}, \mathrm{1967b}$ ). Reports from our laboratory and from other investigators have described similar circulatory responses to isometric handgrip exercise in patients with heart disease (Fisher, Nutter, and

Received 2I August 1972.

1 This study was supported by U.S. Public Health Service Grants.
Schlant, I97I ; Helfant, deVilla, and Meister, I97I ; Kivowitz et al., 1971; Krayenbuehl et al., 1972; Mullins et al., 1970). These studies also suggest that isometric stress testing can provoke evidence of decreased left ventricular compliance or dysfunction. In addition, we have used isometric handgrip stress testing at the bedside and during noninvasive cardiac graphic recording to evoke or accentuate indirect physical evidence of cardiac dysfunction in patients with left ventricular myocardial disease (Siegel et al., 1972).

The present report is a qualitative and quantitative assessment of the haemodynamic responses elicited by isometric handgrip exercise in patients with a variety of cardiac diseases studied during cardiac catheterization. The responses to isometric exercise are compared with those obtained during graded treadmill (dynamic) exercise in a number of subjects. These data demonstrate the degree of circulatory stress imposed on the cardiac patient by isometric exercise. Analysis of our findings along with those reported by Helfant et al. (I97I), Kivowitz et al. (1971), and Krayenbuehl et al. (I972) indicate the potential values of isometric handgrip exercise as a noninvasive cardiac stress test. 
TABLE I Functional status of patients tested with isometric handgrip exercise

\begin{tabular}{|c|c|c|c|c|c|c|}
\hline \multirow[t]{2}{*}{ Group } & \multicolumn{4}{|c|}{$N Y H A^{\star}$ functional class } & \multicolumn{2}{|c|}{ Maximal treadmill exercise duration } \\
\hline & No. & $I$ & II & $I I I-I V$ & No. & Minutes \\
\hline I: Normal left ventricular function & 14 & 14 & - & - & Io & $12 \cdot 1$ \\
\hline II: Mitral stenosis & 12 & - & 5 & 7 & 9 & $5 \cdot 8$ \\
\hline \multicolumn{7}{|l|}{ III: Abnormal left ventricular function } \\
\hline Myocardial disease & 15 & - & 5 & I0 & Io & $7 \cdot 3$ \\
\hline Volume overload & 14 & $\mathbf{I}$ & 3 & I0 & I0 & $7 \cdot 0$ \\
\hline Miscellaneous & 17 & 2 & II & 4 & II & $6 \cdot 9$ \\
\hline Total group III & 46 & 3 & 19 & 24 & 31 & $7 \cdot 1$ \\
\hline
\end{tabular}

^ NYHA, New York Heart Association.

\section{Subjects and methods}

Seventy-two patients undergoing routine diagnostic cardiac catheterization were studied. All patients gave informed consent for the performance of cardiac catheterization and isometric stress testing. Fifty of these patients had objective determination of exercise performance using a modified Bruce maximal treadmill exercise test (Bruce et al., 1963). Sixty patients were arbitrarily classified as having normal or abnormal left ventricular function. The criteria used for this classification were: clinical assessment including NYHA functional class; treadmill exercise tolerance; resting cardiac index; and left cineventriculography for the assessment of ventricular size, contraction pattern, and, when possible, the measurement of end-diastolic volume and ejection fraction. Left ventricular end-diastolic pressure was not included in these criteria because it was one of the major variables to be observed during isometric exercise. The patient classification with a distribution of NYHA functional class and exercise tolerance is shown in Table $\mathrm{I}$. The I4 subjects in whom all of the above criteria were normal (group I) included 5 subjects with no demonstrable cardiac disease and 3 each with mild pulmonary stenosis, small interventricular septal defect (less than I.5 to I.O shunt), and interatrial septal defect. Twelve patients with predominant or isolated mitral stenosis (group II) were classified separately because of the inherent difficulty in assessing left ventricular function with this lesion. The remaining 46 subjects in whom one or more of these criteria were abnormal (group III) included 15 patients with left ventricular disease $(9$ with coronary atherosclerotic disease and 6 with nonobstructive cardiomyopathy), I4 with volume loading due to valvular regurgitation ( 9 with aortic regurgitation, 4 with mitral regurgitation, and I with combined aortic and mitral regurgitation), and 17 patients with miscellaneous lesions, including 6 patients with mixed stenotic and regurgitant valvular lesions and 3 with hypertrophic obstructive cardiomyopathy (idiopathic hypertrophic subaortic stenosis).

\section{Cardiac catheterization}

The patients were studied in a fasted state and without premedication. Patients who had been receiving digitalis and/or diuretics received their usual medications on the day before study. A single patient with obstructive cardiomyopathy was receiving propranolol and none of the patients was receiving antiarrhythmic agents. Diagnostic right and left heart catheterization at rest was completed before handgrip testing. In the ro patients studied primarily to evaluate coronary artery anatomy, parenteral atropine sulphate and sublingual nitroglycerin were given before multiple selective coronary artery injections. A minimum of 30 minutes recovery was allowed between the final coronary injection and handgrip exercise testing. Other angiographic studies were performed after the exercise. Intracardiac and vascular pressures were recorded through saline-filled catheters using Statham ${ }_{23} \mathrm{Db}$ strain gauges and a photographic recorder (Electronics for Medicine, Model DR-12). Cardiac outputs were measured by indicator dilution (Cardiogreen dye) or the Fick technique using standard procedures. Monoplane ventricular volumes and ejection fraction were calculated from left cineventriculograms by the method of Kennedy, Trenholme, and Kasser (1970).

\section{Isometric handgrip testing}

During preparatory phases of the catheterization procedure the patients' maximal voluntary handgrip contraction was determined with a calibrated spring-type dynamometer. The arm, usually the left, not employed for catheter placement was used for handgrip testing. After control recordings of intracardiac pressures and electrocardiogram were obtained, the patient was asked to sustain either 25 per cent maximal voluntary handgrip contraction for five minutes (46 tests) or 75 per cent for one minute (57 tests). Thirty-one patients performed both 25 and 75 per cent maximal tests with at least to minutes of recovery time allowed between contractions. The patients were encouraged to maintain normal respiration and were observed in order to detect the performance of a simultaneous Valsalva manoeuvre. Cardiac output was measured during the third to fifth minutes of 25 per cent maximal voluntary contraction tests. Control determination of cardiac output was performed immediately before the 25 per cent test. Peak haemodynamic responses were measured for both 25 and 75 per cent tests. 
TABLE 2 Heart rate and pressure responses to isometric handgrip exercise

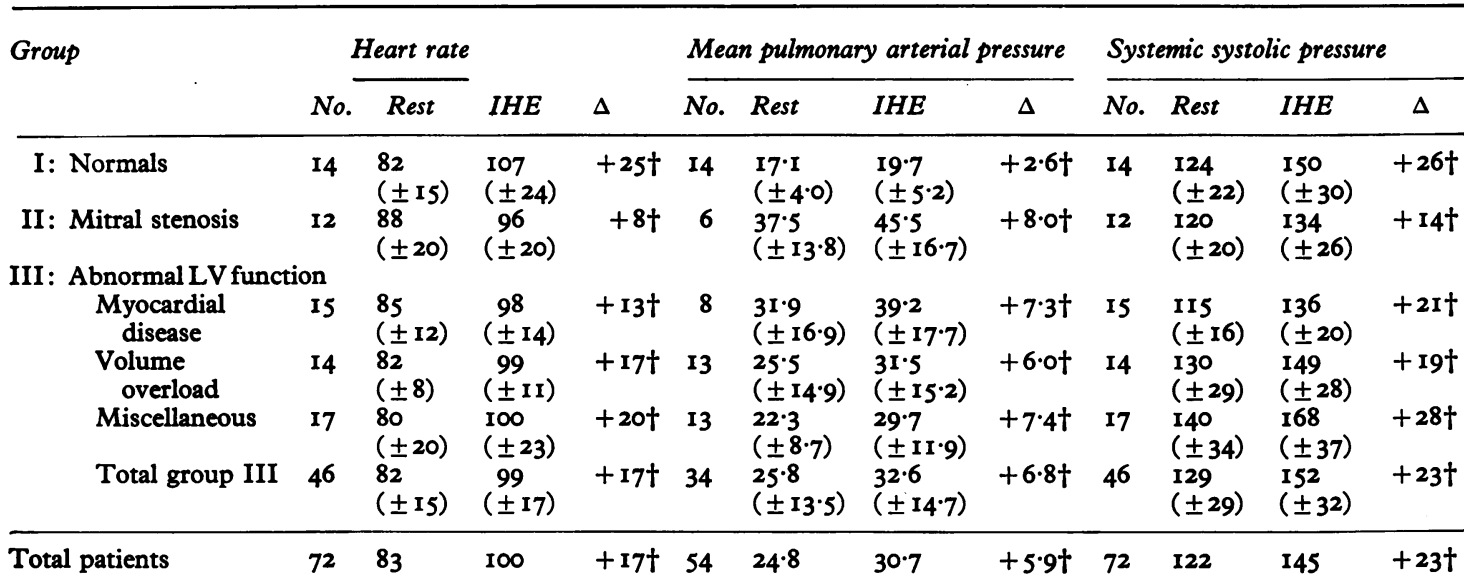

IHE = Maximal value during isometric handgrip exercise; values in parentheses are one standard deviation. $+P<0.05$.

TABLE 3 Clinical and haemodynamic data from patients with abnormal LV function and normal resting $L V$ end-diastolic pressure (Group IIIA)

\begin{tabular}{|c|c|c|c|c|c|}
\hline Response to IHE & Cardiac diagnosis & $\begin{array}{l}\text { Age } \\
(y r)\end{array}$ & $\begin{array}{l}\text { NYHA } \\
\text { functional } \\
\text { class }\end{array}$ & $\begin{array}{l}\text { Treadmill } \\
\text { duration } \\
\text { (min) }\end{array}$ & $\begin{array}{l}\text { Cardiac } \\
\text { index } \\
\left(l . / \min / m^{2}\right)\end{array}$ \\
\hline \multirow{4}{*}{$\begin{array}{l}\text { Abnormal (raised LV } \\
\text { end-diastolic pressure) }\end{array}$} & I : Cardiomyopathy (non-obstructive) & $3 \mathbf{I}$ & II & $10 \cdot 3$ & $4 \cdot 10$ \\
\hline & $\begin{array}{l}\text { 2: Rheumatic heart disease (aortic regurg., mild mitral } \\
\text { stenosis) }\end{array}$ & 53 & III & $9 \cdot 0$ & $\mathbf{I} \cdot 77$ \\
\hline & $\begin{array}{l}\text { 3: Rheumatic heart disease (aortic and mitral regurg., } \\
\text { mitral stenosis) }\end{array}$ & 34 & III & $8 \cdot 0$ & $1 \cdot 60$ \\
\hline & 4: Rheumatic heart disease (mitral regurg.) & 58 & III & - & I·02 \\
\hline \multirow[t]{6}{*}{$\begin{array}{l}\text { Normal (little or no } \\
\text { change in LV end- } \\
\text { diastolic pressure) }\end{array}$} & $\begin{array}{l}\text { 5: Rheumatic heart disease (mitral regurg., stenosis) } \\
\text { 6: Rheumatic heart disease (aortic regurg., mild mitral } \\
\text { stenosis) }\end{array}$ & $\begin{array}{l}21 \\
29\end{array}$ & II & $\overline{7 \cdot 8}$ & $\begin{array}{l}3.50 \\
4.43\end{array}$ \\
\hline & 7: Rheumatic heart disease (mitral regurg., and stenosis) & 63 & III & $3 \cdot 0$ & $2 \cdot 12$ \\
\hline & 8: Post-repair gunshot wound of LV & 37 & II & $9 \cdot 0$ & I.97 \\
\hline & $\begin{array}{l}9 \text { Traumatic mitral regurgitation } \\
\text { Io: Idiopathic aortic regurgitation } \\
\text { II: Coronary atherosclerotic heart disease (angina) }\end{array}$ & $\begin{array}{l}40 \\
25 \\
48\end{array}$ & $\begin{array}{l}\text { II } \\
\text { I } \\
\text { III }\end{array}$ & $\begin{array}{l}9 \cdot 0 \\
9 \cdot 0 \\
6 \cdot 0\end{array}$ & $\begin{array}{l}2 \cdot 64 \\
2 \cdot 40 \\
2 \cdot 51\end{array}$ \\
\hline & 12: Coronary atherosclerotic heart disease (angina) & 40 & III & $5 \cdot 8$ & $2 \cdot 31$ \\
\hline & 13: Essential hypertension and interatrial septal defect & 67 & III & - & $2 \cdot 10$ \\
\hline
\end{tabular}

IHE = Isometric handgrip exercise.

* Maximal exercise duration score.

$\mathrm{EDV}=$ end-diastolic volume index $\left(\mathrm{ml} / \mathrm{m}^{2}\right)$.

$E F=$ ejection fraction. 


\begin{tabular}{|c|c|c|c|}
\hline No. & Rest & $I H E$ & $\Delta$ \\
\hline 5 & $\begin{array}{l}9 \cdot 0 \\
( \pm 6 \cdot 5)\end{array}$ & $\begin{array}{c}8 \cdot 2 \\
( \pm 7 \cdot 2)\end{array}$ & -0.8 \\
\hline 12 & $\begin{array}{c}9.8 \\
( \pm 4 \cdot 5)\end{array}$ & $\begin{array}{l}9 \cdot 9 \\
( \pm 5 \cdot 8)\end{array}$ & +0.1 \\
\hline 13 & $\begin{array}{l}20.8 \\
( \pm 10.3)\end{array}$ & $\begin{array}{l}30.9 \\
( \pm 13.4)\end{array}$ & + 10. It \\
\hline 10 & $\begin{array}{l}19 \cdot 1 \\
( \pm 12 \cdot 6)\end{array}$ & $\begin{array}{l}25 \cdot 7 \\
( \pm 14 \cdot 4)\end{array}$ & $+6.6 \dagger$ \\
\hline 13 & $\begin{array}{l}14 \cdot 8 \\
( \pm 8 \cdot 4\end{array}$ & $\begin{array}{l}19.5 \\
( \pm 10.8)\end{array}$ & $+4.7 \dagger$ \\
\hline 36 & $\begin{array}{l}18.2 \\
( \pm 10.4)\end{array}$ & $\begin{array}{l}25.3 \\
( \pm 13.4)\end{array}$ & $+7 \cdot 1 \dagger$ \\
\hline 53 & 15.4 & $20 \cdot 2$ & $+4.8 \dagger$ \\
\hline
\end{tabular}

\begin{tabular}{|c|c|c|c|}
\hline \multirow{2}{*}{\multicolumn{2}{|c|}{$\begin{array}{l}\text { LV end-diastolic } \\
\text { pressure }(\mathrm{mm} \mathrm{Hg})\end{array}$}} & \multicolumn{2}{|c|}{ Left cineventriculography } \\
\hline & & \multirow[t]{2}{*}{ Chamber size } & \multirow{2}{*}{ Contraction pattern } \\
\hline Rest & $I H E$ & & \\
\hline 4 & 35 & $\begin{array}{l}\text { Enlarged } \\
\quad(E D V \text { I62) }\end{array}$ & Hypokinetic (EF 0.37) \\
\hline 8 & I9 & $\begin{array}{l}\text { Enlarged } \\
\quad(E D V \text { I72) }\end{array}$ & Hypokinetic (EF 0.32) \\
\hline 7 & 17 & $\begin{array}{l}\text { Enlarged } \\
\text { (EDV 104) }\end{array}$ & Normal (EF 0.67) \\
\hline II & 18 & $\begin{array}{l}\text { Enlarged } \\
\quad(E D V \text { 135) }\end{array}$ & Normal (EF 0.58) \\
\hline 7 & 5 & Normal & Normal \\
\hline 8 & 7 & Normal & Normal \\
\hline I0 & II & $\begin{array}{l}\text { Enlarged } \\
\quad \text { (EDV 102) }\end{array}$ & Hypokinetic (EF 0.36) \\
\hline 3 & 5 & Normal & $\begin{array}{l}\text { Localized akinetic } \\
\text { area }\end{array}$ \\
\hline 7 & I0 & Normal & Normal \\
\hline 9 & I I & Normal & Normal \\
\hline 10 & II & $\begin{array}{l}\text { Normal } \\
\quad \text { (EDV 65) }\end{array}$ & Normal (EF 0.75) \\
\hline 12 & II & $\begin{array}{l}\text { Normal } \\
\quad(E D V \text { 90) }\end{array}$ & Normal (EF 0.59) \\
\hline 8 & Io & Normal & Normal \\
\hline
\end{tabular}

\section{Treadmill exercise testing}

Dynamic exercise testing was performed on a treadmill using three-minute stages of progressive, graded activity and the total exercise time (Treadmill Duration Score) was recorded. Scalar Frank lead orthogonal electrocardiograms were continuously recorded. Arterial blood pressure was recorded by sphygmomanometry immediately at the conclusion of each stage, and oxygen consumption was determined during the final minute of each stage using a Douglas bag and Beckman $\mathrm{O}_{2}$ and infrared $\mathrm{CO}_{2}$ analysers.

\section{Results}

The patients were in general able to sustain a 25 per cent maximal test for five minutes but some could sustain only a 50-60 per cent maximal voluntary contraction for one minute during the attempted 75 per cent test. The isometric contraction did not interfere with continuous haemodynamic monitoring. Occasional premature ventricular contractions were noted, but no other dysrhythmias or complications occurred during or immediately after isometric handgrip exercise.

Peak haemodynamic responses were generally seen at or near the completion of the exercise test. Maximal heart rate, mean pulmonary arterial pressure, and systemic systolic arterial pressure responses during isometric exercising were similar for both 25 per cent $(5 \mathrm{~min}$ ) and 75 per cent maximal voluntary contraction (I $\mathrm{min}$ ) testing. Peak heart rate increased by 14 beats a minute during 25 per cent maximal voluntary contraction (mean response from $84-98$ beats a minute) and by $I 8$ beats a minute during 75 per cent maximal voluntary contraction (85-I02). Mean pulmonary artery pressure increased by $5.9 \mathrm{mmHg}(24.9-30.8 \mathrm{mmHg})$ and by 7.3 $\mathrm{mmHg}(25 \cdot 2-32.6)$; and systolic arterial pressure increased by $24 \mathrm{mmHg}$ (125-149) and by $26 \mathrm{mmHg}$ (123-149) during 25 and 75 per cent maximal contraction, respectively. The isometric contraction exercise values for all of these variables differed significantly from control when tested with a paired $t$ test. The haemodynamic results are therefore expressed as pooled values from both levels of testing. Only the data from a 75 per cent maximal voluntary contraction were selected in those patients performing both 25 and 75 per cent maximal contraction tests. Systemic arterial pressure is expressed as systolic pressure because aortic pressures were not simultaneously recorded in patients in whom left ventricular systolic and diastolic pressures were being recorded. In contrast to dynamic exercise, during which diastolic pressure remains relatively unchanged, the 22 patients in whom aortic pressures were measured during isometric handgrip exercise demonstrated equivalent increases in systolic, dias- 


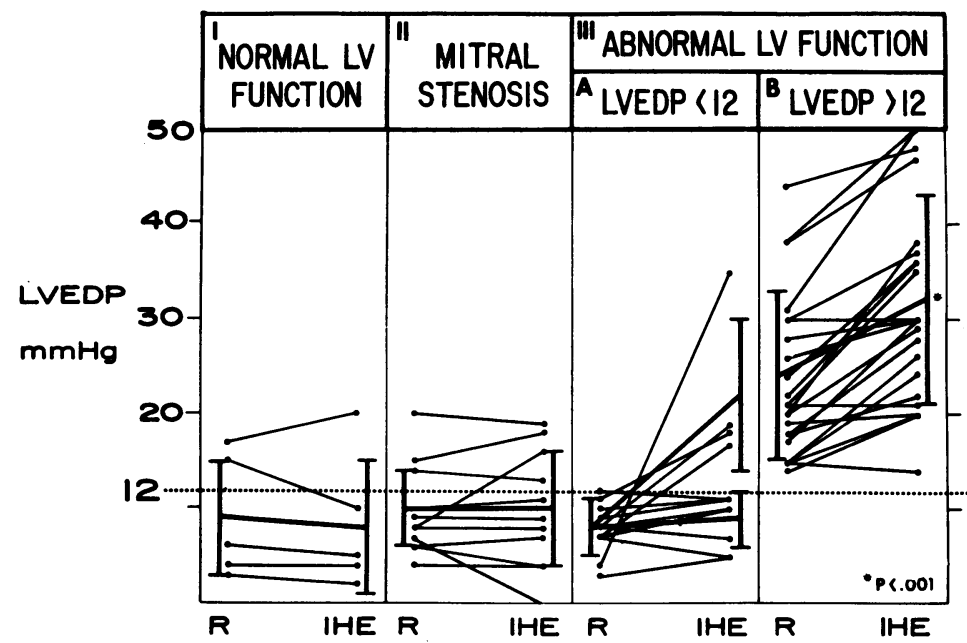

FIG. Individual responses of left ventricular end-diastolic pressure (LVEDP) to isometric handgrip are shown for patients with normal and abnormal left ventricular function (see text for definitions) and with mitral stenosis. The two patients groups on the right-hand side had abnormal left ventricular function and are divided according to the presence of normal $(<12 \mathrm{mmHg}$ ) or abnormal ( $>I 2 \mathrm{mmHg}) L V E D$ pressures at rest. $R=$ resting control LVEDP; IHE = maximal LVEDP value during isometric handgrip exercise. The heavy horizontal bars represent the mean change in LVEDP for each group and the heavy vertical bars represent \pm one standard deviation.

tolic, and mean aortic pressure. Mean aortic pressure increased by $22 \mathrm{mmHg}$ ( 96 to $\mathrm{I} 18 \mathrm{mmHg}$ ) in these patients.

The resting and maximum values during isometric handgrip exercise for heart rate, mean pulmonary artery pressure, systolic arterial pressure, and LV end-diastolic pressure are given for the various patient groups in Table 2. Resting values for heart rate and systolic arterial pressure were the same for normal and abnormal groups. Isometric handgrip exercise resulted in significant increases of these variables in all groups. Mean heart rate increased by $3 \mathrm{I}$ per cent in normals, by $2 \mathrm{I}$ per cent in patients with abnormal left ventricular function, and by 9 per cent in patients with mitral stenosis. In the mitral stenosis group, 2 patients with chronic atrial fibrillation showed 25 and 33 per cent increases in ventricular rate during isometric handgrip exercise, whereas a single patient with atrial flutter did not increase ventricular rate. Systolic arterial pressure

TABLE 4 Clinical and haemodynamic data from patients in groups $I$ and II with raised resting $L V$ end-diastolic pressure

\begin{tabular}{|c|c|c|c|c|c|}
\hline Group & Cardiac diagnosis & $\begin{array}{l}\text { Age } \\
(y r)\end{array}$ & $\begin{array}{l}\text { NYHA } \\
\text { functional } \\
\text { class }\end{array}$ & $\begin{array}{l}\text { Treadmill } \\
\text { duration } \\
\text { (min) }\end{array}$ & $\begin{array}{l}\text { Cardiac } \\
\text { index }\end{array}$ \\
\hline \multirow{5}{*}{$\begin{array}{l}\text { I: Normal LV func- } \\
\text { tion } \\
\text { II: Mitral stenosis }\end{array}$} & Atypical chest pain with normal coronary arteriography & 39 & I & 13.5 & $3 \cdot 19$ \\
\hline & Small interventricular septal defect & 16 & I & 15.7 & $2 \cdot 58$ \\
\hline & $\begin{array}{l}\text { Rheumatic heart disease (mitral stenosis, mild aortic } \\
\text { regurg.) }\end{array}$ & 28 & III & - & 3.66 \\
\hline & $\begin{array}{l}\text { Rheumatic heart disease (mitral stenosis, mild mitral } \\
\text { regurg.) }\end{array}$ & 60 & III & $3 \cdot 2$ & $2 \cdot 60$ \\
\hline & $\begin{array}{l}\text { Rheumatic heart disease (mitral stenosis, mild aortic } \\
\text { regurg.) }\end{array}$ & 23 & III & $6 \cdot 2$ & $2 \cdot \infty$ \\
\hline
\end{tabular}


similarly showed a $2 \mathrm{I}$ per cent rise in normals, an 18 per cent rise in patients with abnormal left ventricular function, and a 12 per cent rise in mitral stenosis. The mean pulmonary arterial pressure at rest was raised in all abnormal groups and was highest in patients with mitral stenosis. A small but significant increase in pulmonary arterial pressure $(15 \%)$ occurred in normal subjects. All abnormal groups showed larger and roughly equivalent rises in pulmonary artery pressure $(26 \%)$ with isometric handgrip exercise. The average LV end-diastolic pressure at rest in 5 subjects with normal cardiac function and in patients with predominent mitral stenosis was normal. In these groups end-diastolic pressure did not significantly increase during isometric handgrip exercise. In patients with abnormal left ventricular function the average LV end-diastolic pressure was raised at rest and showed a significant increase during isometric handgrip exercise. The behaviour of $\mathrm{LV}$ end-diastolic pressure in individual patients during exercise is graphically illustrated in the Figure. Here patients classified as having abnormal LV function (group III) are subdivided on the basis of the resting $\mathrm{LV}$ end-diastolic pressure in order to show the several patterns of response seen during isometric handgrip exercise. The patients in group IIIA (normal resting LV end-diastolic pressure) showed 2 distinct patterns of response (Table 3 ): 4 patients showed obvious increases in LV end-diastolic pressure to clearly abnormal levels during isometric handgrip exercise, whereas 9 patients showed little or no change in end-diastolic pressure. Patients in group IIIB (abnormal resting LV end-diastolic pressure) had relatively consistent increases in these pressures during handgrip. Unexpectedly, two of the patients who fulfilled all of our criteria for normal LV function (group I) had a raised LV end-diastolic pressure as

\begin{tabular}{lllll}
\multicolumn{2}{l}{$L V$ end-diastolic pressure } & \multicolumn{2}{l}{ Left cineventriculography } \\
\cline { 1 - 1 } Rest & IHE & & Chamber size & Contraction pattern \\
\hline 17 & I9 & Normal & Normal \\
15 & I0 & Normal & Normal \\
20 & I9 & Normal & Hypokinetic \\
14 & 13 & Normal & Normal \\
15 & I8 & Normal & Hypokinetic \\
\hline
\end{tabular}

an isolated, unexplained abnormality. Three patients with predominant mitral stenosis (group II) also had a raised resting $L V$ end-diastolic pressure. The clinical and haemodynamic features of these 5 patients are summarized in Table 4.

The effects of isometric handgrip exercise on stroke volume, cardiac output, cardiac index, and total peripheral and pulmonary resistances are shown in Table 5. The 5 normal subjects in whom cardiac output determinations were recorded during isometric handgrip exercise did not include the two patients with abnormal resting LV end-diastolic pressure. In this normal group the average resting stroke volume and cardiac output were higher and total systemic and pulmonary resistance lower than in patients with mitral stenosis or abnormal left ventricular function. In all patient groups isometric handgrip exercise had an inconsistent effect on stroke volume, cardiac output, and total resistances. This variability was noted in data derived from both indicator dilution and Fick methods. In the 5 normal subjects stroke volume increased in 3 and cardiac output increased in 4 ; while in 23 abnormals stroke volume increased in 12 and cardiac output increased in 19. In 7 patients in the mitral stenosis group, cardiac output increased in 6 while stroke volume increased in 4 . In 5 normal subjects total peripheral resistance rose in 3 and fell in 2 while total pulmonary resistance rose in 4 and fell in one. In the 19 abnormal subjects total peripheral resistance rose in 12 and fell in 7 patients, while pulmonary resistance rose in 7 , fell in $I I$, and remained unchanged in 2. The average response in all subjects studied was a small increase in stroke volume $(5 \%)$, a modest but significant increase in cardiac output $(18 \%$ ) (due mainly to the increased heart rate), and essentially no change in total peripheral resistance or total pulmonary resistance.

The effect of isometric handgrip exercise upon the mean mitral diastolic pressure gradient was determined in ro patients with mitral stenosis. The mean diastolic gradient was $14.3 \mathrm{mmHg}$ at rest and increased to $17.6 \mathrm{mmHg}(23 \%, \mathrm{P}<0.01)$ during isometric handgrip exercise.

\section{Isometric and treadmill testing}

Table 6 presents the mean product of systolic pressure and heart rate(HP.SP) during submaximal treadmill exercise for 50 patients and during isometric handgrip exercise for all 72 patients. Oxygen consumption and the duration of treadmill exercise is indicated for two levels of treadmill activity. There was a significant difference in the duration of treadmill exercise, maximal oxygen consumption, and HR.SP index between the normal and abnormal groups during maximal treadmill exercise. When the same 
TABLE 5 Cardiac output and vascular resistance responses to isometric handgrip exercise

\begin{tabular}{|c|c|c|c|c|c|c|c|c|c|c|c|c|}
\hline \multirow[t]{2}{*}{ Patient group } & \multicolumn{4}{|c|}{ Stroke volume } & \multicolumn{4}{|c|}{ Cardiac output } & \multicolumn{4}{|c|}{ Cardiac index } \\
\hline & No. & Rest & $I H E$ & $\Delta$ & No. & Rest & $I H E$ & $\Delta$ & No. & Rest & $I H E$ & $\Delta$ \\
\hline I: Normals & 5 & $\begin{array}{l}69 \\
( \pm 15)\end{array}$ & $\begin{array}{l}79 \\
( \pm 38)\end{array}$ & +10 & 5 & $\begin{array}{l}6 \cdot 65 \\
( \pm I \cdot 76)\end{array}$ & $\begin{array}{l}8 \cdot 34 \\
( \pm 3 \cdot 8 I)\end{array}$ & $+1 \cdot 69$ & 5 & $\begin{array}{l}3 \cdot 33 \\
( \pm I \cdot 13)\end{array}$ & $\begin{array}{l}4 \cdot 13 \\
( \pm I \cdot 97)\end{array}$ & +0.80 \\
\hline II: Mitral stenosis & 7 & $\begin{array}{l}56 \\
( \pm 18)\end{array}$ & $\begin{array}{l}62 \\
( \pm 22)\end{array}$ & +6 & 7 & $\begin{array}{l}4 \cdot 36 \\
( \pm I \cdot 09)\end{array}$ & $\begin{array}{l}5 \cdot 26 \\
( \pm 1 \cdot 58)\end{array}$ & $+0.90^{\star}$ & 7 & $\begin{array}{l}2 \cdot 76 \\
( \pm 0 \cdot 70)\end{array}$ & $\begin{array}{l}3 \cdot 35 \\
( \pm I \cdot 18)\end{array}$ & $+0.59^{\star}$ \\
\hline $\begin{array}{l}\text { III: Abnormal LV } \\
\text { function }\end{array}$ & 23 & $\begin{array}{l}59 \\
( \pm 33)\end{array}$ & $\begin{array}{l}59 \\
( \pm 31)\end{array}$ & 0 & 23 & $\begin{array}{l}4 \cdot 52 \\
( \pm I \cdot 66)\end{array}$ & $\begin{array}{l}5 \cdot 18 \\
( \pm 2 \cdot 08)\end{array}$ & $+0.66^{\star}$ & 23 & $\begin{array}{l}2.50 \\
( \pm 0.89)\end{array}$ & $\begin{array}{l}2 \cdot 88 \\
( \pm I \cdot 15)\end{array}$ & $+0.38^{\star}$ \\
\hline Total patients & 35 & 59 & 62 & +3 & 35 & $4 \cdot 80$ & $5 \cdot 66$ & $+0.86^{\star}$ & 35 & $2 \cdot 67$ & $3 \cdot 14$ & $+0.47^{\star}$ \\
\hline
\end{tabular}

$\star \mathbf{P}<0.05$

TABLE 6 Isometric handgrip exercise and treadmill exercise

\begin{tabular}{|c|c|c|c|c|c|c|c|c|c|c|}
\hline \multirow[t]{3}{*}{ Group } & \multicolumn{4}{|l|}{$I H E$} & \multicolumn{5}{|c|}{ Treadmill - stage $I I$} & \multirow{3}{*}{$\begin{array}{l}\text { Treadmil } \\
\text { duration } \\
(\text { min) }\end{array}$} \\
\hline & \multicolumn{4}{|c|}{$H R \cdot S P$ index $\left(\times 10^{3}\right)$} & \multicolumn{4}{|c|}{$H R \cdot S P$ index $\left(\times I O^{3}\right)$} & \multirow[t]{2}{*}{$q \hat{O}_{2}$} & \\
\hline & No. & Rest & $\begin{array}{l}\text { Peak } \\
\text { exercise }\end{array}$ & $\Delta$ & No. & Rest & $\begin{array}{l}\text { Peak } \\
\text { exercise }\end{array}$ & $\Delta$ & & \\
\hline I: Normals & I4 & $10 \cdot 4$ & $16 \cdot I$ & $+5 \cdot 7$ & 6 & $9 \cdot 4$ & $22 \cdot 2$ & $+12 \cdot 8$ & $15 \cdot 9$ & $6 \cdot 0$ \\
\hline II: Mitral stenosis & 12 & 10.4 & $13 \cdot 0$ & $+2 \cdot 6$ & 5 & $12 \cdot 2$ & $21 \cdot 4$ & $+9 \cdot 2$ & $16 \cdot 1$ & $6 \cdot 0$ \\
\hline \multicolumn{11}{|l|}{ III: Abnormal LV function } \\
\hline Myocardial disease & 15 & IO. I & 13.7 & +3.6 & 7 & 10.5 & $22 \cdot 2$ & $+\mathrm{Ir} \cdot 7$ & $15 \cdot 0$ & $6 \cdot 0$ \\
\hline Volume overload & 14 & $10 \cdot 2$ & $14 \cdot 3$ & $+4 \cdot 1$ & 6 & $9 \cdot 9$ & $24 \cdot 3$ & +14.4 & $15 \cdot 8$ & $6 \cdot 0$ \\
\hline Miscellaneous & 17 & II $\cdot \mathbf{I}$ & $16 \cdot 3$ & $+5 \cdot 2$ & 8 & 10.0 & 19.5 & $+9 \cdot 5$ & $16 \cdot 7$ & $6 \cdot 0$ \\
\hline Total group III & 46 & 10.6 & $15 \cdot 1$ & +4.5 & 21 & $10 \cdot 1$ & $21 \cdot 8$ & $+11 \cdot 7$ & $15 \cdot 8$ & $6 \cdot 0$ \\
\hline Total patients & 72 & IO. I & 14.5 & $+4 \cdot 4$ & 32 & $10 \cdot 3$ & $2 \mathrm{I} \cdot 8$ & $+11 \cdot 5$ & 15.9 & $6 \cdot 0$ \\
\hline
\end{tabular}

$\mathrm{HR} \cdot \mathrm{SP}$ index =(heart rate) $\cdot\left(\right.$ systemic systolic pressure); $\mathrm{q} \hat{\mathrm{O}}_{2}=$ maximal oxygen consumption (ml $\left./ \mathrm{kg} / \mathrm{min}\right)$.

level of moderate treadmill exercise (stage II, 6 minutes) is compared, however, there was no difference between the normal or abnormal groups in terms of oxygen consumption or HR.SP index. There was also little difference in the HR.SP index of normal and abnormal groups at rest and during isometric exercise, though the HR.SP index in mitral stenosis patients was somewhat less than in other patients during both types of exercise. The average HR.SP index increase for all patients during isometric handgrip exercise $\left(4.4 \times 10^{3}\right)$ was, however, much less than that observed during a moderate level of treadmill exercise $\left(\mathrm{II} \cdot 5 \times \mathrm{IO}^{3}\right)$.

\section{Discussion}

The reflex circulatory adjustments previously described with isometric (static) exercise in normal subjects were readily elicited in the present investigation during isometric handgrip exercise in patients with both normal and abnormal left ventricular function. In both normal and abnormal patient groups isometric handgrip resulted in significant increases of heart rate and systemic arterial pressure. The patients with normal LV function had the largest responses in rate and systemic pressure, similar in magnitude to those reported in normal young subjects (Tuttle and Horvath, 1957; Lind et al., 1964; Freyschuss, 1970) and in the normal patient group described by Helfant et al. (197I).

Two levels of static exercise $(75 \%$ maximal voluntary contraction held for one minute and $25 \%$ held for five minutes) were chosen for study because: (a) contractions greater than 15 per cent maximal voluntary contraction are known to cause progressive haemodynamic changes to the point of fatigue (Donald et al., 1967); (b) the chosen durations approximate the points of fatigue; (c) cardiac output determinations could be performed during the fiveminute 25 per cent maximal voluntary contraction 


\begin{tabular}{|c|c|c|c|c|c|c|c|}
\hline \multicolumn{4}{|c|}{ Total systemic resistance } & \multicolumn{4}{|c|}{ Total pulmonary resistance } \\
\hline No. & Rest & $I H E$ & $\Delta$ & No. & Rest & $I H E$ & $\Delta$ \\
\hline 5 & $\begin{array}{l}17 \cdot 6 \\
( \pm 6 \cdot 8)\end{array}$ & $\begin{array}{l}17 \cdot 8 \\
( \pm I I \cdot 8)\end{array}$ & +0.2 & 5 & $\begin{array}{l}2 \cdot 4 \\
( \pm 0.4)\end{array}$ & $\begin{array}{l}2.5 \\
( \pm 0.9)\end{array}$ & +0.1 \\
\hline 2 & 18.6 & 23.6 & +5.0 & 4 & $12 \cdot I$ & $12 \cdot 8$ & +0.7 \\
\hline 19 & $\begin{array}{l}22 \cdot 4 \\
( \pm 8 \cdot 9)\end{array}$ & $\begin{array}{l}23 \cdot 1 \\
( \pm 8 \cdot 8)\end{array}$ & +0.7 & $2 \mathbf{I}$ & $\begin{array}{l}7 \cdot 5 \\
( \pm 5 \cdot 5)\end{array}$ & $\begin{array}{l}7 \cdot 6 \\
( \pm 5 \cdot 3)\end{array}$ & +0.1 \\
\hline 26 & $2 I \cdot 2$ & $22 \cdot 2$ & $+I \cdot 0$ & 30 & $7 \cdot 3$ & 7.5 & +0.2 \\
\hline
\end{tabular}

\begin{tabular}{|c|c|c|c|c|c|}
\hline \multicolumn{5}{|c|}{ Treadmill-maximum } & \multirow{3}{*}{$\begin{array}{l}\text { Treadmill } \\
\text { duration }\end{array}$} \\
\hline \multicolumn{4}{|c|}{$H R \cdot S P$ index $\left(\times 10^{3}\right)$} & \multirow[t]{2}{*}{$q \hat{O}_{2}$} & \\
\hline No. & Rest & Exercise & $\Delta$ & & \\
\hline 10 & $9 \cdot I$ & $30 \cdot 2$ & $+2 I \cdot I$ & $30 \cdot 6$ & $12 \cdot I$ \\
\hline 9 & II $\cdot \mathbf{I}$ & 20.4 & $+9 \cdot 3$ & $16 \cdot 8$ & $5 \cdot 8$ \\
\hline 10 & $10 \cdot 7$ & $25 \cdot 2$ & +14.5 & $17 \cdot 4$ & $7 \cdot 3$ \\
\hline I0 & 10.0 & $23 \cdot I$ & $+13 \cdot 1$ & 18.4 & $7 \cdot 0$ \\
\hline II & $10 \cdot 0$ & $23 \cdot 6$ & +14.4 & $17 \cdot 0$ & $6 \cdot 9$ \\
\hline 31 & $10 \cdot 2$ & $24 \cdot 0$ & $+13 \cdot 7$ & $17 \cdot 6$ & $7 \cdot I$ \\
\hline 50 & $10 \cdot 2$ & $24 \cdot 6$ & $+14 \% 4$ & $19 \cdot 8$ & $7 \cdot 8$ \\
\hline
\end{tabular}

tests; and (d) possible qualitative or quantitative differences in the haemodynamic responses could be observed. Haemodynamic changes developed much more slowly during 25 per cent maximal voluntary contraction tests, but the average peak heart rate and blood pressure responses were similar to the peak responses during 75 per cent contraction tests. These findings are compatible with studies in normal subjects which have shown that the rate of development of haemodynamic changes depends on the relative strength of contraction (\% maximal voluntary contraction) and that similar peak blood pressure responses may occur when contractions of varying intensity are held to fatigue (Lind and McNicol, 1967b).

All I4 patients in the normal group responded to isometric handgrip exercise in a consistent manner, but several patients in the abnormal groups showed little or no increase in rate or systemic pressure. These poor responses may be due to several factors: (a) the failure of the patient to co-operate in performing a true maximal voluntary contraction could lead to the subsequent performance of a contraction that represented a very low percentage of the true maximal contraction strength; (b) though only a few of these subjects received atropine premedication, many were taking digitalis and/or diuretics, which might alter the isometric cardiovascular reflex; (c) some component(s) of the reflex may be depressed in the presence of cardiac failure. The latter two explanations appear more reasonable since Lind and McNicol (1967b) showed that modest increases in rate and pressure occur with as little as Io per cent maximal voluntary contraction static exercise in normal subjects. There was no apparent correlation between the absolute magnitude of the handgrip contraction and the haemodynamic responses either in this study or in normal subjects (Freyschuss, 1970). Review of recent reports (Helfant et al., 1971; Kivowitz et al., 1971) confirms our observation that some patients with heart disease fail to increase heart rate or blood pressure during isometric exercise.

Patients with predominant or isolated mitral stenosis responded to exercise in a distinctive manner. The heart rate and blood pressure responses were attenuated during both isometric handgrip exercise and dynamic exercise (see Table 6). Thus, in patients with mitral stenosis left ventricular stress is limited during handgrip exercise. It does cause a modest increase in the mitral diastolic gradient.

The small increase in stroke volume and the increase in heart rate during 25 per cent maximal voluntary contraction isometric testing produced a modest increase in cardiac output in all patient groups. This suggests that both heart rate and augmented cardiac sympathetic activity play a role in increasing the cardiac output. Studies by Freyschuss (1970) suggest that the increased heart rate is related to a withdrawal of vagal inhibition. Earlier studies in normal subjects also showed an increase in cardiac output due to an increase in heart rate with little change in stroke volume (Donald et al., 1967; MacDonald et al., I966). The patients with heart disease reported in this study, and those reported by Helfant et al. (197I) and Kivowitz et al. (197I) also demonstrate inconsistent changes in cardiac output and stroke volume. Individual responses in cardiac output observed in these studies should be interpreted cautiously since isometric exercise greater than 15 per cent maximal voluntary contraction causes non-steady state haemodynamics, limiting the validity of cardiac output calculation by either Fick or indicator dilution techniques. This may explain the observed variation in the direction and magnitude of stroke volume and cardiac output 
changes despite reasonably consistent increases in heart rate.

Lind et al. (1964) and MacDonald et al. (1966) showed that in normal young subjects calculated total peripheral resistance is relatively unaffected during isometric handgrip exercise. Some investigations of the isometric cardiovascular reflex mechanism have suggested that the increase in systemic arterial pressure is in part due to increased alpha-adrenergic activity in addition to the increase in cardiac output (Freychuss, 1970). In our patients with heart disease the changes in total systemic and pulmonary resistance were quite variable. Further data on handgrip exercise-induced changes in systemic resistance are reported by Kivowitz et al. (197I) and can be calculated from systolic pressure and cardiac output data reported by Helfant $e t$ al. (I97I). Compared to our patients, the average change (increase) in systemic resistance was greater, but these patients also showed considerable individual variation in the magnitude and direction of change. The individual variability in resistance calculations may in part be due to the problem of accurately measuring cardiac output. Several factors appear to contribute to the pressor response observed during isometric handgrip exercise, and in this context Lind and McNicol (1967b) have proposed that any available mechanism will be employed to increase the perfusion pressure and blood flow to a muscle group undergoing sustained contraction. It is probable that arterial resistance is increased in many vascular beds, including the contracting muscles, inactive muscles, and skin, while resistance is decreased in other vascular beds, as yet poorly defined.

An abnormal LV end-diastolic pressure may represent either raised end-diastolic volume, decreased myocardial compliance, or a combination of these factors. When these conditions are present an increase in aortic pressure usually evokes or accentuates the abnormal increase in $\mathrm{LV}$ end-diastolic pressure (Ross and Braunwald, 1964; Linhart et al., I969).

Isometric haemodynamic exercise causes little or no change in LV end-diastolic pressure in normal subjects. Direct LV end-diastolic pressure measurements were available in only 5 of the 14 patients who fulfilled our criteria for normal LV function, and in this group average LV end-diastolic pressure was unchanged during isometric handgrip exercise. Pulmonary artery mean and diastolic pressures recorded in all normal subjects increased only slightly, confirming that left ventricular filling pressure is minimally affected during isometric handgrip exercise. In addition, the 9 normal subjects reported by Helfant et al. (197I) had an average increase in LV end-diastolic pressure of only $2 \mathrm{mmHg}$ during isometric handgrip pressure. Krayenbuehl et al. (1972) also reported a $2 \mathrm{mmHg}$ average increase in enddiastolic pressure in 13 patients described as having little or no left ventricular loading. Furthermore, these 13 patients had evidence of increased contractility during exercise. Of interest are the end-diastolic pressure responses seen during isometric handgrip exercise in our 2 patients who had a raised resting end-diastolic pressure as an isolated, unexplained abnormality (Table 4, group I). LV enddiastolic pressure increased only $2 \mathrm{mmHg}$ in one of these patients and decreased to normal in the other patient, suggesting that $\mathrm{LV}$ function was normal or only minimally impaired.

In patients with mitral stenosis $\mathrm{LV}$ end-diastolic pressure did not change significantly though their left atrial and pulmonary arterial pressures increased. The 3 patients with mitral stenosis with raised resting LV end-diastolic pressure (shown in group II of the Figure and Table 4) presumably had LV dysfunction or abnormal compliance, possible due to healed rheumatic myocarditis or other unknown factors, since the degree of associated valvular regurgitation was minor. Even in these 3 patients, isometric handgrip exercise did not significantly increase LV end-diastolic pressure.

Patients classified as having abnormal left ventricular function (group III) significantly increased both LV end-diastolic and pulmonary arterial pressures during handgrip. In these patients the increase in the latter during isometric handgrip exercise appears to result primarily from an increase in left atrial pressure, though minor changes may also occur as a result of increased pulmonary blood flow. Patients classified as having abnormal LV function, but with normal resting $\mathrm{LV}$ end-diastolic pressure (group IIIA in the Figure and Table 3) showed two patterns of response to isometric exercise. Four patients (I-4) increased LV end-diastolic pressure to distinctly abnormal levels, while 9 patients $(5-13)$ showed little or no change. The type of response appears to correlate best with the LV angiographic findings (Table 3). Two patients (3 and 4) with abnormal LV end-diastolic pressures during isometric handgrip exercise had normal ejection fractions from enlarged left ventricles; however, each of these patients also had severe valvular regurgitation which should be exaggerated by the increased afterload during handgrip. There were 2 patients (7 and 8) with normal left ventricular end-diastolic pressures at rest and during isometric handgrip exercise, who had abnormal ventricular contraction patterns. Case 7 had significant mitral stenosis which appears to limit LV stress during exercise. Case 8 showed a vigorous and normal LV contraction pat- 
tern except for the localized area of previous surgical repair. Patients with abnormal LV function and an abnormal resting LV end-diastolic pressure (group IIIB in Figure) significantly increased end-diastolic pressure during handgrip. Three of these patients were exceptions to this rule: in one, the systemic pressure failed to rise during exercise and the other two had clinical and ventriculography data suggesting left ventricular infarction (one) and hypertrophy (one), but did not have cardiac failure or ventricular dysfunction. In these patients the abnormal resting end-diastolic pressure may be explained on the basis of a decrease in ventricular compliance though the failure further to increase LV end-diastolic pressure during a systemic pressor stress remains unexplained.

The LV end-diastolic pressure responses described above are quite comparable to the responses reported by Helfant et al. (197I), Kivowitz et al. (I97I), and Krayenbuehl et al. (1972). Of particular interest, among the 74 patients described by these three groups, there were 5 patients in whom LV end-diastolic pressure was normal at rest but increased to distinctly abnormal levels during handgrip exercise. This type of response, also seen in 4 of our patients, suggests that the exercise may be a useful stress test during cardiac catheterization, particularly in patients with suspected ventricular dysfunction in whom resting $\mathrm{LV}$ end-diastolic pressure is normal or borderline raised.

It, therefore, appears that if one excludes patients with significant mitral stenosis, an abnormal LV end-diastolic pressure can be elicited or accentuated by isometric handgrip in patients with dysfunction or decreased compliance of the left ventricle. A significant increase in $\mathrm{LV}$ end-diastolic pressure during isometric handgrip exercise seemed to correlate best with angiographic evidence of ventricular dysfunction. These direct haemodynamic data and similar findings from other investigators (Helfant et al., I97I ; Kivowitz et al., 197r ; Krayenbuehl et al., 1972; Mullins et al., 1970) support the work from our laboratory showing that isometric handgrip exercise can selectively provoke or accentuate gallop sounds and abnormal apical diastolic pulsations in patients with left ventricular disease (Siegel et al.: 1972). Our studies have shown that the exercise can easily be performed at the bedside or in the graphics laboratory as a stress test for the detection of ventricular dysfunction.

The haemodynamic data from this study clearly show that the heart rate, cardiac output, and HR.SP index responses to submaximal isometric handgrip exercise are smaller than the increase in these variables during submaximal dynamic (treadmill) exercise. We have also previously shown the same rela- tion when the HR.SP index is calculated during maximal treadmill exercise and during a maximal voluntary isometric contraction (Siegel et al., 1972). The application of isometric handgrip exercise for cardiac stress testing does have the advantage of producing a conspicuous increase in both systolic and diastolic systemic pressure. Furthermore, isometric handgrip exercise can be performed in a reproducible, graded manner in the supine patient while permitting the continuous recording of physical, phonocardiographic, and haemodynamic data. Peak responses can be readily elicited in one minute using a 75 per cent maximal voluntary contraction test.

Significant arrhythmias or other complications were not encountered during the performance of these 103 handgrip tests in 72 patients, many of whom had cardiac failure and myocardial disease. Since the induction of angina pectoris and ventricular arrhythmias has been reported during isometric handgrip exercises (Siegel et al., 1972; Matthews et al., 1971), certain precautions are necessary for its safe application. The electrocardiogram should be continuously monitored and isometric handgrip exercises terminated if angina pectoris or rhythm disturbances develop. The nature of the haemodynamic responses elicited during isometric handgrip exercises suggests that this exercise testing or the spontaneous performance of significant isometric stress is best avoided in patients with recent myocardial infarction, severe systemic hypertension, significant cerebral vascular disease, or recurrent cardiac dysrhythmias.

The authors wish to express gratitude for the treadmill exercise testing performed in The Cardiac Function Laboratory under the supervision of Dr. Charles A. Gilbert, and for the technical assistance provided in the Cardiac Catheterization Laboratory by Miss Carolyn Mears, Mrs. Dorothy Brewer, R.N., and Mrs. Harriette Matthews.

\section{References}

Bruce, R. A., Blackmon, J. R., Jones, J. W., and Strait, G. (1963). Exercise testing in adult normal subjects and cardiac patients. Pediatrics, 32, 742.

Donald, K. W., Lind, A. R., McNicol, G. W., Humphreys, P. W., Taylor, S. H., and Staunton, H. P. (1967). Cardiovascular responses to sustained (static) contractions. Circulation Research, 20, Suppl. I, I5.

Fisher, M., Nutter, D., and Schlant, R. (197I). Hemodynamic evaluation of isometric exercise testing in cardiac patients (abstract). Circulation, 44, Suppl. I I, 50.

Freyschuss, U. (1970). Cardiovascular adjustment to somatomotor activation. Acta Physiologica Scandinavica, 79, Suppl. 342, $1-63$.

Helfant, R. H., deVilla, M. A., and Meister, S. G. (1971). Effect of sustained isometric handgrip exercise on left ventricular performance. Circulation, 44, 982. 
Kennedy, J. W., Trenholme, S. E., and Kasser, I. S. (1970). Left ventricular volume and mass from single-plane cineangiocardiogram. A comparison of anteroposterior and right anterior oblique methods. American Heart fournal, 80, 343.

Kivowitz, C., Parmley, W. W., Donoso, R., Marcus, H., Ganz, W., and Swan, H. J. C. (197I). Effects of isometric exercise on cardiac performance: the grip test. Circulation, 44, 994 .

Krayenbuehl, H. P., Rutishauser, W., Schoenbech, M., and Amende, I. (1972). Evaluation of left ventricular function from isovolumic pressure measurements during isometric exercise. American fournal of Cardiology, 29, 323.

Lind, A. R., and McNicol, G. W. (1967a). Circulatory responses to sustained hand-grip contractions performed during other exercise, both rhythmic and static. Fournal of Physiology, 192, 595.

Lind, A. R., and McNicol, G. W. (1967b). Muscular factors which determine the cardiovascular response to sustained and rhythmic exercise. Canadian Medical Association Fournal, 96, 706.

Lind, A. R., Taylor, S. H., Humphreys, P. W., Kennelly, B. M., and Donald, K. W. (1964). Circulatory effects of sustained voluntary muscle contraction. Clinical Science, 27, 229.

Linhart, J. W., Hildner, F. J., Barold, S. S., and Samet, P. (1969). Myocardial function in patients with coronary artery disease. American fournal of Cardiology, 23, 379.
MacDonald, H. R., Sapru, R. P., Taylor, S. H., and Donald, K. W. (I966). The effect of intravenous propranolol on the systemic circulatory response to sustained handgrip. American fournal of Cardiology, 18, 333.

Matthews, O. A., Atkins, J. M., Houston, J. D., Blomqvist, G., and Mullins, C. B. (1971). Arrhythmias induced by isometric exercise (handgrip) (abstract). Clinical Research, 19, 23.

Mullins, C. B., Leshin, S. J., Mierzwiak, D. S., Matthews, O. A., and Blomqvist, G. (1970). Sustained forearm contraction (hand-grip) as a stress test for evaluation of left ventricular function (abstract). Clinical Research, 18, 322.

Ross, J., Jr., and Braunwald, E. (1964). The study of left ventricular function in man by increasing resistance to ventricular ejection with angiotensin. Circulation, 29, 739.

Siegel, W., Gilbert, C. A., Nutter, D. O., Schlant, R. C., and Hurst, J. W. (1972). The use of isometric handgrip for the indirect assessment of left ventricular function in patients with coronary atherosclerotic heart disease. American Fournal of Cardiology, 30, 48 .

Tuttle, W. W., and Horvath, S. M. (1957). Comparison of effects of static and dynamic work on blood pressure and heart rate. Fournal of Applied Physiology, 10, 294.

Requests for reprints to Dr. Donald O. Nutter, Emory University School of Medicine, Thomas K. Glenn Memorial Building, 69 Butler Street, S.E., Atlanta, Georgia 30303, U.S.A. 